\title{
ANTIOXIDANT CAPACITY OF EUGENOL DERIVATIVES
}

María E. Hidalgo* and Carlos De la Rosa

Facultad de Ciencias, Universidad de Valparaíso, Gran Bretaña 1111, Valparaíso, Chile

Héctor Carrasco, Wilson Cardona and Claudio Gallardo

Facultad de Ecología y Recursos Naturales, Universidad Andrés Bello, Los Fresnos 52, Viña del Mar, Chile

Luis Espinoza

Departamento de Química, Universidad Técnica Federico Santa María, Avenida España 1680, Valparaíso, Chile

Recebido em 3/7/08; aceito em 14/1/09; publicado na web em 28/7/09

\begin{abstract}
Toxicity and antioxidant capacity of eugenol derivatives (E2 = 2-Methoxy-4-[1-propenylphenyl]acetate, E3 = 4-Allyl-2methoxyphenylacetate, E4 = 4-Allyl-2-methoxy-4-nitrophenol, E5 = 5-Allyl-3-nitrobenzene-1,2-diol, E6 = 4-Allyl-2-methoxy-5nitrophenyl acetate) were evaluated in order to determine the influence of the sustituents. E2-E6 were synthesized from eugenol (E1). E1 was extracted from cloves oil, and E2-E6 were obtained through acetylation and nitration reactions. Antioxidant capacity evaluated by DPPH (1, 1-Diphenyl-2-picrylhydrazil) and ORAC fluorescein demonstrated that E1 and E5 have a higher capacity and the minor toxicity evaluated by red blood cells haemolysis and the Artemia saline test. In accordance with our results, the compound's (E1-E5) use in the pharmaceutical, cosmetic and or food industries could be suggested.
\end{abstract}

Keywords: eugenol derivatives; antioxidant capacity.

\section{INTRODUCTION}

Phenols, specially flavonoids and antocians show a great capacity to scavenge free radicals that causes the oxidative stress. ${ }^{1-4}$ They have anti-inflammatory, antiallergic, antitrombotic, antimicrobial and antineoplasic activity. ${ }^{5-8}$

The eugenol (E1) is a phenolic derivative commonly known as nail essence ${ }^{9}$ that can also be extracted from pepper, bay leaves, cinnamon, nutmeg, camphor and some natural oils. ${ }^{10} \mathbf{E} 1$ is a yellow oily liquid with a characteristic fragrance which is soluble in alcohol and presents a low solubility in water. ${ }^{9}$ Several studies have demonstrated the antioxidant capacity of the eugenol and related compounds (like isoeugenol) to inhibit the lipidic peroxidation induced by reactive oxygen species. ${ }^{11,12}$ It also inhibits the superoxide radical formation in the xanthine-xanthine oxidase system. ${ }^{13} \mathbf{E} 1$ can inhibit the hydroxyl radical generation, and can prevent the $\mathrm{Fe}^{2+}$ oxidation in the Fenton reaction that generates the radical. This is one of the most aggressive radicals for the human tissue. ${ }^{14}$ In high concentrations it has a bactericidal effect that has been attributed to phenol groups: by degeneration of proteins can damage the cellular membrane, however, at low concentrations it tends to stabilize cellular membranes. The pharmacologic effects of the eugenol are complex and depend on the free eugenol concentration to which the human tissue is exposed. ${ }^{15}$

The aim of this study was to evaluate the antioxidant and toxicologist properties of these pure derivatives (Figure 1) as a contribution to possible future applications.

\section{EXPERIMENTAL}

\section{Synthesis of eugenol's derivatives}

Eugenol (E1) was obtained from cloves smell, according to standard procedure. ${ }^{16}$

*e-mail: maria.hidalgo@uv.cl

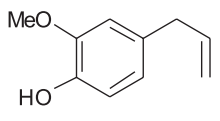

(E1)

4-Allyl-2-methoxypheno<smiles>C=CCc1ccc(OC(C)=O)c(OC)c1</smiles>

(E3)

4-Allyl-2-methoxyphenyl acetate<smiles>C=CCc1cc(O)c(O)c([N+](=O)[O-])c1</smiles>

(E5)<smiles>C/C=C\c1ccc(OC(C)=O)c(OC)c1</smiles>

2-Methoxy-4-(1-propenyl)phenyl acetate<smiles>C=CCc1cc(OC)c(O)c([N+](=O)[O-])c1</smiles>

(E4)

4-Allyl-2-methoxy-6-nitrophenol<smiles>C=CCc1cc(OC)c(OC(C)=O)cc1[N+](=O)[O-]</smiles>

(E6)
5-Allyl-3-nitrobenzene-1,2-diol

Figure 1. Structures of eugenol derivatives

4-allyl-2-methoxy-6-nitrophenol (E4) and 5- allyl-3-nitrobenzene-1, 2-diol (E5) ${ }^{17}$

Eugenol $1.5 \mathrm{~g}(9.15 \mathrm{mmol})$ was dissolved in dichloromethane (30 $\mathrm{mL}$ ) and was added to a mixture stirred which contained $4.5 \mathrm{~g}$ (33 $\mathrm{mmol})$ of potassium hydrogen sulphate, $3.0 \mathrm{~g}$ (35.3 mmol) of sodium nitrate and $3.5 \mathrm{~g}$ of wet silica to $50 \% \mathrm{P} / \mathrm{P}$; the mixture was left to continue at room temperature for $5.5 \mathrm{~h}$. The complete disappearance of the starting product was confirmed by means of the thin layer chromatography (TLC) method (ethyl acetate: n-hexane 1:3). The reacted mixture was filtered through silica and the solid was washed with dichloromethane, and the solvent evaporated in vacuum to give reddish oil. Pure product was obtained by CC (5:1-3:1 ethyl acetate in hexane), which gave $1.10 \mathrm{~g}$ of the desired compound $\mathbf{E 4}(63.2 \%$ yield) and $0.043 \mathrm{~g}(2.9 \%)$ of E5. 
4-allyl-2-methoxyphenyl acetate $(\boldsymbol{E} 3)^{17}$

To a stirred solution of eugenol $10.00 \mathrm{~g}(6.10 \mathrm{mmol})$ in pyridine $(2.00 \mathrm{~mL})$ was added dichloromethane $(20 \mathrm{~mL})$ and $10 \mathrm{mg}$ of $4-\mathrm{N}, \mathrm{N}$ dimethylaminopyridine (DMAP). The solution was stirred at room temperature for $30 \mathrm{~min}$. Acetic anhydride was added and the reaction was left to continue for $1 \mathrm{~h}$ and after this period, the complete disappearance of the starting product was confirmed by means of the thin layer chromatography (TLC) method (ethyl acetate: n-hexane 1:3).

To the stopped reaction a $10 \%$ solution of potassium hydrogen sulphate was added and extracted with dichloromethane. The organic phase was washed with water $(3 \times 20 \mathrm{~mL})$ until $\mathrm{pH} 7$, dried with anhydrous $\mathrm{Na}_{2} \mathrm{SO}_{4}$ and vacuum evaporated. Pure product was obtained by column chromatography (5:1-3:1 ethyl acetate in hexane), which gave the desired compound with quantitative yield.

\section{4-allyl-2-methoxy-5-nitrophenyl acetate $(\boldsymbol{E} 6)^{17}$}

To a stirred solution of 4-allyl-2-methoxyphenyl acetate $200 \mathrm{mg}$ $(0.97 \mathrm{mmol})$ in dichloromethane $(5 \mathrm{~mL})$ was carefully added at $0{ }^{\circ} \mathrm{C} 2 \mathrm{~mL}$ of a sulphonitric mixture, which was prepared by adding concentrated nitric acid on concentrated sulphuric acid. The reaction was left to continue for $30 \mathrm{~min}$ and after this period, the complete disappearance of the starting product was confirmed by means of the thin layer chromatography (TLC) method (ethyl acetate: n-hexane 1:3).

The reaction stops by adding $15 \mathrm{~mL}$ water. The organic layer was washed with water $(3 \times 20 \mathrm{~mL})$ in order to extract the excess of acid present and dried with anhydrous $\mathrm{Na}_{2} \mathrm{SO}_{4}$, filtered, and the solvent was evaporated at low pressure obtaining an oily product, which was purified by Flash Chromatography (ethyl acetate: $n$-hexane) which allowed obtaining $89 \mathrm{mg}(35 \%)$ of the mixture of pure isomers, then the mixture of isomers was re-crystallized from a of ethyl acetate/n-hexane mixture.

\section{2-methoxy-4-(prop-1-enyl) phenyl acetate (E2)}

To a stirred solution of (E)-2-methoxy-4-(prop-1-enyl) phenol (isoeugenol) $10.00 \mathrm{~g}(0.061 \mathrm{~mol})$ in pyridine $(2.00 \mathrm{~mL})$ was added dichloromethane $(20 \mathrm{~mL})$ and $10 \mathrm{mg}$ of $4-N, N$-dimethylaminopyridine (DMAP). The solution was stirred at room temperature for $30 \mathrm{~min}$. Acetic anhydride was added and the reaction was left to continue for $1 \mathrm{~h}$ and after this period, the complete disappearance of the starting product was confirmed by means of the thin layer chromatography (TLC) method (ethyl acetate: n-hexane 1:3).

To the stopped reaction a $10 \%$ solution of potassium hydrogen sulphate was added and extracted with dichloromethane. The organic phase was washed with water $(3 \times 20 \mathrm{~mL})$ until $\mathrm{pH} 7$, dried with anhydrous $\mathrm{Na}_{2} \mathrm{SO}_{4}$ and vacuum evaporated. Pure product was obtained by column chromatography (5:1-3:1 ethyl acetate in hexane), which gave the desired compound with quantitative yield.

\section{ORAC Assay}

The sample $(20 \mu \mathrm{L})$, in phosphate buffer $(5 \mu \mathrm{L}, 75 \mathrm{mM}, \mathrm{pH}$ 7.4), and main reagent ( $365 \mu \mathrm{L} \mathrm{FL}, 48 \mathrm{nM}$ ) were mixed and incubated for $30 \mathrm{~s}$ before recording the initial fluorescence (f0), FL and 2,2'-azobis(2-aminopropane)dihydrochloride (AAPH) were prepared with $75 \mathrm{mM}$ phosphate buffer at $\mathrm{pH} 7.4$. Fluorescence readings were taken at $0.5 \mathrm{~s}$ and then every minute thereafter $(\mathrm{f} 1, \mathrm{f} 2, \mathrm{f} 3, \ldots)$ during $30 \mathrm{~min}$. The final ORAC values were calculated using a regression equation between the Trolox concentration and the net area under the FL decay curve, and were expressed as Trolox equivalents as micromole per liter or per gram. The area under curve (AUC) was calculated as: $\mathrm{AUC}=1+\mathrm{f} 1 / \mathrm{f} 0+\mathrm{f} 2 / \mathrm{f0}+\mathrm{f} 3 / \mathrm{f} 0+\mathrm{f} 4 / \mathrm{f} 0+\ldots+\mathrm{f} 34 / \mathrm{f} 0+$ $\mathrm{f} 35 / \mathrm{f0}$ where $\mathrm{fO}$ is the initial fluorescence reading at $0 \mathrm{~min}$ and $\mathrm{fi}$ is the fluorescence reading at time i. The resulting AUC was obtained by subtracting the AUC of the blank from that of the sample. The relative ORAC value (Trolox equivalents) was calculated as: ${ }^{18}$
[(AUCSample- AUCBlank)/(AUCTrolox- AUCBlank) x (molarity of Trolox/molarity of sample)]

\section{$\underline{D P P H}$}

The antiradical activities of various antioxidants were determined using the free radical, 1,1-Diphenyl-2-picrylhydrazyl (DPPH). In its radical form, DPPH has an absorption band at $515 \mathrm{~nm}$ which disappears upon reduction by an antiradical compound. ${ }^{19}$

\section{Toxicity test: Eggs from Artemia saline}

(Class: Crustacea, Subclass: branchiopoda; Super order: anostraca, Family: artemidae, Genus: artemia). The cysts of Artemia saline were incubated in filtered sea water (micropore $0.22 \mu \mathrm{m}$ ) and oxygenated during $45 \mathrm{~min}$ at $30{ }^{\circ} \mathrm{C}$ temperature in a thermo regulate bath and fit to $\mathrm{pH} 8$ in $\mathrm{NaOH} 0.1 \mathrm{M}$. After $24 \mathrm{~h}$, the eclosionated nauplius (first stage of the Artemia saline) are in conditions for the accomplishment of the toxicity tests. ${ }^{20}$

\section{Toxicity in red cell model}

Red blood cells of healthy adult donors were used. Shortly after collection, the heparinised blood was centrifuged at 2,000 g and both the plasma and buffy coat discarded. The remaining red cells were washed three times with an isotonic solution $(0.15 \mathrm{M}$ $\mathrm{NaCl}$ on $0.01 \mathrm{M}$ sodium phosphate (PBS), $\mathrm{pH} 7.4$ ). The red cells were resuspended to approximately $2 \% \mathrm{v} / \mathrm{v}$, kept at $6{ }^{\circ} \mathrm{C}$ and used in the next $72 \mathrm{~h}$. The percentage of haemolysis was determined immediately after irradiation by measuring the haemoglobin liberated in the medium from solutions containing $0.4 \%$ red cells. Measurements were carried out at 540, 560, 577, 630 and $700 \mathrm{~nm}$, and the concentrations were evaluated according to the Winterbourn equation. ${ }^{21,22}$

\section{Statistic analysis}

Variance analysis ANOVA.

\section{RESULTS AND DISCUSSION}

These phenolic compounds (Figure 1) present hydroxyl groups in their aromatic ring that exert their antioxidant properties. The antioxidant potential of each derivative was determined by means of the quenching rate constant $(\mathrm{k})$ for the fluorescence decay. The ORAC values (Table 1) showed a significant difference between E1 and E5 compared to the other compounds. This demonstrates the antioxidant properties of these derivatives, caused by the presence of phenolic groups in the aromatic ring which form a phenolic radical. This radical, which would become stabilized by resonance with the double bonds of the aromatic ring, allows the formation of radicals in two positions: ortho $(o)$ and para $(p)$ of

Table 1. ORAC-FL values $(100 \mu \mathrm{M})$ derivatives

\begin{tabular}{lcc}
\hline Derivative & Value ORAC-FL & SD \\
\hline E1 & 1.9854 & $\pm 1.1^{*} 10^{-3}$ \\
E2 & 1.8619 & $\pm 5.4^{*} 10^{-3}$ \\
E3 & 1.9057 & $\pm 5.7 * 10^{-3}$ \\
E4 & 1.9622 & $\pm 3.6^{*} 10^{-3}$ \\
E5 & 2.0727 & $\pm 3.2^{*} 10^{-2}$ \\
E6 & 1.6998 & $\pm 1.5^{*} 10^{-3}$ \\
\hline
\end{tabular}


the aromatic ring from the phenolic group (Figure 2). E1 and E5 present the highest number of resonance structures, contributing to the stability of the phenolic radical. E1-E5 present sustituents with inductive effect -I (electron-attractive), such as the methoxy group and the nitro group that tends to destabilize the phenolic radical (Figure 3).<smiles></smiles><smiles>C=CCc1cc(OC)c(OC(C)=O)cc1[N+](=O)[O-]</smiles>
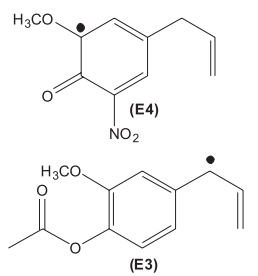<smiles>C/C=C/c1ccc(OC(C)=O)c(OC)c1</smiles>

Figure 2. a) Radical formation in phenol derivatives E1 and E4, b) allyl radical formation in acetate derivatives
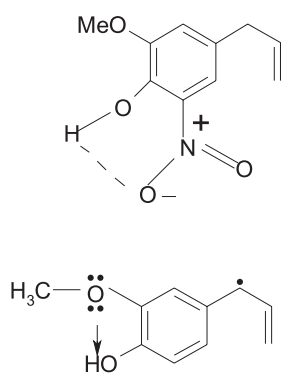

Figure 3. Nitro and methoxy effect

Between both effects (inductive effect and resonance), the resonance presents a greater importance in the stability of the radical. Similarly, E4 is the phenolic derivative that presents the minor antioxidant effect, possibly due to the presence of the nitro group that allows the formation of interactions between the hydrogen and the $\mathrm{OH}$ radical, which would prevent the formation of the phenolic radical (Figure 3).

According to Figure 4 by DPPH method, E1 and E5 derivatives cause a significant reduction of absorbance. The derivatives E1 and E4 present a methoxyl group (electron donor for resonant effect) in ortho $(o)$ with respect to $\mathrm{OH}$ group, which allows to stabilize

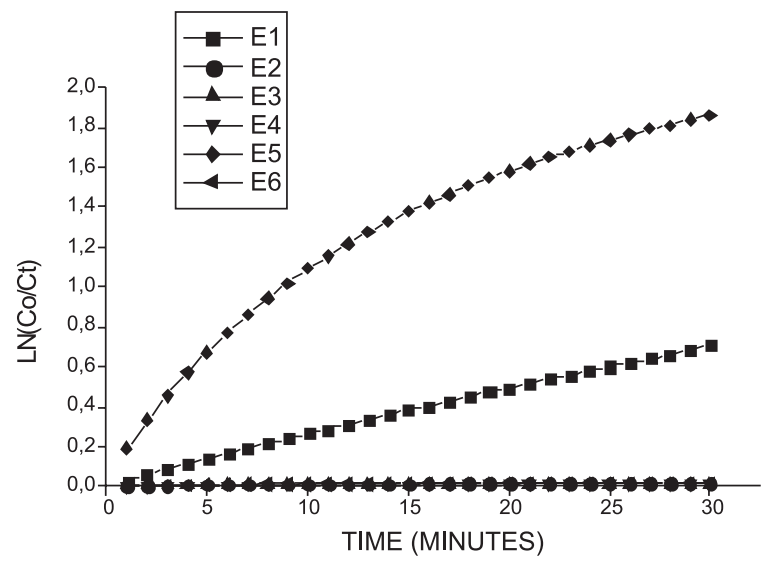

Figure 4. Consumption rate constant $(k)$ determination from radical absorption $(100 \mu M)$ at $517 \mathrm{~nm}$. (DPPH method) the phenolic radical, contributing to the formation and stability of the radical (Figure 2a). E2-E3-E6 present low quenching constant values, indicating small antioxidant capacity caused, probably, due to low probability of allyl radicals' formation, which could become stabilized by resonance with the aromatic ring or the double bonds (Figure 2b). E2-E3-E6 have substituent with inductive effect -I (electron-attractive), as the acetate, methoxyl and nitro groups, which tend to destabilize the formation of an allyl radical, but due to the distance with respect to the allyl radical, their effect is insignificant.

The toxicity results in the red cell model provided information about the haemolysis caused by the eugenol derivatives in the plasmatic membrane of the erythrocyte (Table 2).

Table 2. Hemolysis percentage for eugenol derivatives

\begin{tabular}{lcccccc}
\hline \multicolumn{7}{c}{ Hemolysis percentage } \\
Concentration ppm & E1 & E2 & E3 & E4 & E5 & E6 \\
\hline 1 & 0.36 & 0.37 & 0.33 & 0.34 & 0.32 & 0.34 \\
10 & 0.53 & 0.44 & 0.55 & 0.43 & 0.39 & 0.48 \\
25.25 & 0.58 & 0.52 & 0.61 & 0.51 & 0.42 & 0.55 \\
100 & 0.73 & 0.72 & 0.74 & 0.69 & 0.51 & 0.72 \\
\hline
\end{tabular}

The values obtained are lower than $1 \%$, which indicate that in general they are not toxic since the haemolysis percentage is comparable to the mechanical damage caused by manipulating the blood. By the lack of knowledge of the derivative plasmatic concentration that these derivatives could reach, a concentration of $25.25 \mu \mathrm{M}$ was considered, which is 1000 times higher to the plasmatic concentration of the reference compound 3,4-methylendioxymetamfetamine (MDMA) that was chosen considering its structural similarity with the derivatives in study, therefore, they are slightly toxic or its toxicity is insignificant with respect to other types of damage that undergoes the erythrocyte. The results obtained in the bioassay with Artemia saline, indicate that E5 (5-allyl-3-nitrobenzene-1,2-diol) is the derivative that presents highest $\mathrm{LD}_{50}(89.1 \pm 32.2)$, which means it requires a higher concentration to cause a significant effect in comparison to E3 that presented the lowest $\operatorname{LD}_{50}(16.2 \pm 3.82)$, resulting to be the most toxic of the eugenol derivatives, possibly due to the presence of the acetate and methoxy group (Table 3 ).

Table 3. LD50 values for eugenol derivatives

\begin{tabular}{lcc}
\hline $\mathrm{LD}_{50}$ & $x^{2}$ & Confidence limit \\
\hline 17.8 & 1.68 & \pm 3.77 \\
31.6 & 1.48 & \pm 5.72 \\
16.2 & 1.70 & \pm 3.82 \\
40.7 & 0.85 & \pm 9.14 \\
89.1 & 0.20 & \pm 32.2 \\
31.6 & 1.18 & \pm 6.74 \\
\hline
\end{tabular}

A concordance between the results from both antioxidant tests was observed, demonstrating that E1 and E5 are those that present higher antioxidant capacity.

E5 is the less toxic eugenol derivative according to both methods used. The eugenol derivatives, in red blood cells model, have toxicity lower than $1 \%$ (toxicity), thus are only slightly toxic against the erythrocyte membrane. 


\section{CONCLUSIONS}

The results of both antioxidant assays demonstrated that E1 and E5 have the greatest capacity as free radical scavengers, due to the presence of one or more phenolic groups in the aromatic ring, which are essential for its antioxidant capacity. E5 has the lowest toxicity, nevertheless eugenol's derivatives exhibited a haemolysis percentage lower than $1 \%$, which is a very low toxicity level for the red cell membranes.

\section{ACKNOWLEDGMENTS}

The authors thank Universidad Andrés Bello (grant DI-UNAB 18-08/R) and Universidad Técnica Federico Santa Maria (grant DGIP 13.08.59) for financial support.

\section{REFERENCES}

1. Heim, K. E.; Tagliaferro, A. R.; Bobilya, D. J.; J. Nutr. Biochem. 2002, $13,572$.

2. Espin, J. C.; Sololer-Rivas, C.; Wichers, H. J. ; García-Viguera, C. ; J. Agric. Food Chem. 2000, 48, 1588.

3. Kuskoski, E. M.; Vega, J. M.; Rios, J. J.; Fett, R.; Troncoso, A.; Asuero, A. G.; J. Agric. Food Chem. 2003, 51, 5450.

4. Moyer, R.; Hummer, K.; Finn, C.; Frei, B.; Wrolstad, R.; J. Agric. Food Chem. 2002, 50, 519.

5. Prior, R. I.; Cao, G.; Martin, A.; Sofic, E.; Mce-Wan, J.; O’brien, C.; Lischner, N.; Ehlenfeldt, M.; Kalt, W.; Krewer, G.; Mainland, C. M.; J. Agric. Food Chem. 1998, 46, 2686.
6. Ross, J. A.; Kasum, C. M.; Annu. Rev. Nutr. 2002, 22, 19.

7. Sánchez-Moreno, C.; Alimentaria 2002, 29.

8. Satué-Gracia, M. T.; Heinonen, M.; Frankel, E. N.; J. Agric. Food Chem. 1997, 45, 3362.

9. Garza, E.; Toranzo, J. M.; ADM. 1998, 55, 46.

10. Remington's Pharmaceutical Sciences; Mack Publishing Co: Pennsylvania, 1990, p. 1056.

11. Pabla, T.; Gulati, M. S.; Mohan, U.; J Indian Soc Pedod Prev Dent. 1997, 15, 134.

12. Reddy, A.; Lokesh, B. R.; Mol. Cell. Biochem. 1994, 137, 1.

13. Toda, S.; Ohnishi, M.; Kimura, M.; Toda, T.; Planta Med. 1994, 60, 282.

14. Sukumaran, K.; Unnikrishnan, M. C.; Kuttan, R.; Indian Physiol Pharmacol. 1994, 38, 306.

15. Markowitz, K.; Moynihan, M. L.; Kim, S. K.; Oral Surg. Oral Med. Oral Pathol. 1992, 73, 729.

16. Ntamila, M. S.; Hassanali, A.; J. Chem. Educ. 1976, 53, 263.

17. Carrasco, H.; Espinoza, L.; Cardile, V.; Gallardo, C.; Cardona, W.; Lombardo, L.; Catalán, K.; Cuellar, M.; Russo, A.; J. Braz. Chem. Soc. 2008, 19, 543.

18. Dávalos, A.; Gómez-Cordovés, C.; Bartolomé, B.; J. Agric. Food Chem. 2004, 52, 48.

19. Kim, D-O.; Lee, K. W.; Lee, H. J.; Lee, C. Y.; J. Agric. Food Chem. 2002, 50, 3713.

20. Persoone, G.; Zetschrift fur Angewandte Zoologie 1991, 78, 235.

21. Winterbourn, C.; Methods Enzymol. 1990, 186, 265.

22. Kahn, G.; Fleischaker, B.; J. Investigative Dermatol. 1971, 56, 85. 